\title{
Perception, Loss, and Rivalry Termination
}

\author{
Author: Craig Carpenter \\ Faculty Mentor: Michael Greig, Department of Political Science, College of Arts and \\ Sciences, University of North Texas \\ Department and College Affiliation: Department of Political Science, St Mary’s \\ College of Maryland
}




\section{Bio:}

Craig Carpenter's hometown is Bowie, Maryland. He attends college at St. Mary’s

College of Maryland, where he is currently a senior majoring in Political Science and Sociology. His academic interests include international relations and peace and conflict studies. After completing his undergraduate degree he plans to pursue a $\mathrm{PhD}$ in Political Science. 


\begin{abstract}
:
While rivalries account for a relatively small number of dyadic relationships between states, they produce a disproportionately large number of conflicts (Geller 1993). This means that the study of rivalries represents a chance to understand the mechanisms that lead to conflict and thereby reduce the probability of conflicts in the future. In this study, elements of prospect theory are utilized to build a theoretical framework of how states perceive gains and losses. I theorize that states perceive gains and losses relative to their current accumulation of gains or losses. As a result, we would expect to see an increasing value placed on losses and a diminishing value placed on gains as the duration of a rivalry increases. This difference in perception would eventually lead to the pain perceived from losses outstripping the perceived benefits of gains, resulting in rivalry termination. I test the theory that rivalries with severe conflicts in the initial phases of the rivalry will result in shorter rivalry duration. However, the findings of this study do not support the initial theory as higher levels of severity in the initial period of the conflict are related to slightly increased rivalry duration.
\end{abstract}




\section{Introduction}

The study of rivalries, long running dyadic relationships between competing nations, continues to remain relevant even in the current era. Rivalries are a catalyst for conflict. A handful of rivalries accounts for a disproportionate number of militarized interstate disputes (Geller 1993). This means studying rivalries and determining what causes rivalries to end offer the potential to substantially decrease the number of militarized disputes and other conflicts that occur between states. Furthermore, while the termination of rivalries has been studied in depth (Bennett 1996; Gibler 1997; Thompson 1999; Hensel, Goertz, and Diehl 2000; Colaresi 2001), previous works fail to provide a theory to explain the common factors that lead to rivalry termination.

In this paper, I postulate a theory to explain how previously discovered causes of rivalry termination fit together in one cohesive explanation. To do this, I utilize elements of prospect theory to form a theoretical conceptualization of how states perceive losses and gains and how state perceptions of gains and losses lead to rivalry termination.

First, this paper contains a survey of existing research on the termination of rivalries. Second, the paper contains a theoretical framework to explain why rivalries end. Third, it quantitatively measures and empirically tests this framework to determine its accuracy. Fourth, this paper contains an analysis of our results and the implications they have for the study of rivalries

\section{Literature Review}

\section{Literature on Rivalry Termination}

Existing studies of rivalries tend to focus on one of three aspects of rivalries: the factors that cause the initiation of rivalries (Goertz and Diehl 1995; Moaz and Mor 1996; 
Vasquez 1998); the factors that maintain rivalries (Colaresi 2004; Goertz, Jones. and Diehl 2005); or the factors that cause the termination of rivalries (Goertz and Diehl 1995; Bennett 1996; Cornwell and Colaresi 2002). Because it is pertinent to the research conducted here, this paper contains current research that pertains to the end of rivalries.

Some have suggested that rivalries are a process of learning in which changing global circumstances cause changes in the preferences of states and the alternatives available to them (Thompson 1999). Thompson states that, through interaction, rivals learn the preferences, goals, and positions of one another, through a process of trial and error. This process allows for rivals to determine a resolution that is mutually acceptable to one another, thereby resulting in the termination of a rivalry.

Domestic political factors play a role in the end of rivalries. Evidence suggests that regime change facilitates the end of rivalries (Bennett 1998; Colaresi 2001). Bennett (1998) suggests that a greater number of changes in polity allows for more opportunities for policies toward a rival state to change, thus leading to a greater chance for rivalry termination. The importance of domestic political factors is further reinforced by other research that explains that as democratization occurs within a country, the probability of rivalry termination increases (Prins \& Daxecker 2008) and the probability of armed conflict between rivals decreases (Hensel, Goertz, and Diehl 2000). If a country is both democratic and economically developed, the chance of rivalry termination increases (Prins and Daxecker 2008). Lebow (1995) says there are four domestic political conditions which, if present, lead to rivalry termination:

1. A rival leader is committed to domestic reforms; 
2. The reforms proposed by that leader require the assistance of the other rival in the dyad;

3. A rivalry has failed to achieve its goals; and

4. A belief exists that conciliatory gestures will be reciprocated.

Political shocks are recognized as a catalyst for the termination of rivalries (Goertz and Diehl 1995; Goertz and Diehl 2001). Shocks come in a variety of different forms or events, but all share the commonality that they create an intense degree of upheaval in the existing political system (Goertz and Diehl 1995). Colaresi’s (2001) study suggests that global wars are a form of shock that leads to the end of rivalries. The ability of political shocks to cause the end of rivalries is dramatic. Goertz and Diehl (1995) find that over 90 percent of all rivalries end within 10 years of a political shock.

Another proposed reason for the end of rivalries is the effect of security. Bennett (1998) found that rivals who faced a threat from a third party were more likely to terminate their rivalry than those who did not. Other evidence suggests that when states have a method of arbitrating disputes rather than allowing them to escalate to conflict ends rivalries. This evidence is supported by research that intergovernmental organizations with bodies for dispute resolution increase the probability of rivalry termination (Prins and Daxecker 2008).

Issue salience also plays a role in the end of rivalries. Research suggests that reduced issue salience, the importance placed on a particular issue, leads to the end of rivalries (Bennett, 1996; Bennett 1998). However, the salience of issues tends to be measured in physical proximity to the conflict. This finding is in line with Gibbler's (1997) finding that disputes over territory lead to increased duration of rivalries. 
These explanations for what causes rivalries to end represent a diverse array of potential factors that leads to rivalry termination. However, the factors which lead to the termination of rivalries that have already been proposed in the literature lack a single underlying explanation. This paper contains research to provide a unifying explanation for all factors that lead to the termination of rivalries.

\section{Literature on Prospect Theory}

Perception plays an important role in the way states make decisions because the decisions that states make are based on how they perceive and weigh potential gains and losses. Therefore, understanding how states perceive gains and losses leads to a better understanding of when and why states choose to end rivalries. Prospect Theory states that equal amounts of gains and losses are valued differently by individuals. Specifically, losses are valued more heavily than gains (Kahneman and Tversky 1979; Levy 1992; Levy 2000). This means that in a situation where an individual has 100 dollars and has 10 dollars stolen from him, the amount of pain he feels is greater than the amount of joy he would feel if he had 100 dollars and was given 10 dollars.

Prospect Theory also states that an individual's perception of gains and losses are defined by their point of reference (Kahneman and Tversky 1979; Quattrone and Tversky 1988). This means that how an individual weighs gains and losses changes based on the individual's reference point. For example, a man with 100 dollars feels less pain from the loss of 10 dollars than if he had only 50 dollars and suffered a loss of 10 dollars.

\section{Theory}

All rivalries involve a dyadic relationship between two states characterized by repeated hostile interactions, whereby previous interactions affect each subsequent 
interaction (Goertz and Diehl 1992). Each time a state interacts with its rival, a state must choose one of two options: escalation or de-escalation of the rivalry. All possible decisions fall into one of these two categories. While it is also logical to account for situations in which a rival may choose to maintain the status quo choice, maintaining the status quo is by definition defaulting to a previous choice to escalate or de-escalate a conflict, because in either case maintaining parity requires that a state increase or decrease its level of exertion.

Prior to determining a course of action, a state must evaluate potential outcomes. The decision making process occurs in two parts: A state will first frame its decision, then evaluate potential gains and losses (Kahneman and Tversky 1979). Several factors affect the way states value potential gains and losses at each interaction. Among these are socio-cultural factors such as regime types or cultural attitudes towards violence, and systemic factors like the balance of power or the presence of outside threats. All of these factors contribute to the way states frame their circumstances which, in turn, shape the way a state values gains and losses. However, the primary drivers in the process of decision making are the economic, material, and military resources with the social capital available to a state. First, in order to escalate a conflict, a state must exert itself by expending resources. This makes the requirement for resources constant across all states, unlike socio-cultural factors which may vary from region to region and state to state. Second, while the factors that make up a state's base of resources are not finite, they usually increase gradually. For example, global gross domestic product (GDP) grew at an average rate of 2.4 percent over the five year period between 2005 and 2009, and global 
population grew at an average rate of one percent per year in the same five year period (World Bank 2011).

The effect of a requirement to expend resources to escalate a conflict and the near static nature of resources cause gains and losses not to be perceived in accordance with their actual material value. This disparity between material value and perceived value is the result of states evaluating their gains and losses in terms of what the state currently possesses. In order to escalate a conflict, states must exert themselves by expending a variety of resources. The expenditure of these resources constitutes a loss to the state that expends them. For example, once ordnance is expended, it cannot be recouped; once lives are lost, those same lives cannot be replaced; and once the good will of the people has been exhausted, it takes time to recover. The American shells fired during the Korean War cannot be recouped, the lives of German soldiers lost in the Second World War cannot be regained, and the trust of the American in government lost during Vietnam could not be instantly replenished. Not only can resources not be recovered, but if they are spent on escalating a conflict, they cannot be reallocated to other programs, such as social welfare programs or maintenance of infrastructure.

In order to escalate a conflict, a state must incrementally expend more resources. The material value of the losses incurred as the result of this fixed cost increases in a linear fashion, steadily accumulating over time. Refer to Figure 1. The perception of a state's losses, as the result of these expenditures, increases proportionally, however, in comparison to a state's remaining capacity. Therefore, the perceived cost of escalation increases in a non-linear fashion, because the reference point from which a state views its 
potential losses is constantly in flux as the result of the losses from previous interactions. This trend is displayed in Figure 2.

This process can be illustrated in simple terms. If an individual has only \$100 and the person spends $\$ 10$ to purchase a certain good, that individual will only have $\$ 90$ remaining. Therefore, the next time this individual goes to purchase the same good for the same $\$ 10$, he or she is expending proportionally more of his or her total worth. In this case, the first time the individual spends the $\$ 10$ on a good, he is spending 10 percent of his worth, but the second time he or she expends the $\$ 10$ on the same good, he or she is expending 11.1 percent of his/her total worth. If the individual continues to purchase this same good repeatedly, the perception of how much is being spent increases as the amount of money the individual has left decreases. After five iterations, the amount of perceived loss for the same expenditure has doubled.

As a state escalates a rivalry, thus devoting more resources to the conflict, the amount of loss that a state perceives should increase at a much faster rate than the actual loss. This means that periods of continual or rapid escalation should lead directly to a decision by the parties involved to de-escalate the conflict as the amount of perceived loss begins to increase at a greater rate. For example, during the Cold War, the period of detente that began in 1969 is preceded by a five-year period during which U.S. military expenditures grew as a percentage of gross domestic product (Higgs, 1988; World Bank, 2011). Similarly, in the ten-year period before the end of the Cold War in 1989, U.S. military expenditures as a percentage of GDP grew from 5.3 percent to 7.7 percent (Higgs 1988; World Bank 2011). 
In much the same way, states value gains relative to what they are currently. As a state accumulates gains, the material value of these gains increases at a constant rate. This rate accumulates slowly over time, in a linear fashion. Refer to Figure 3. When this steady increase in material gains is coupled with the need to consistently expend the same amount to receive a fixed amount of gain, the perception of the amount being gained does not increase in linear manner. As the amount of accumulated perceived gains increases, states become less willing to exert themselves because the same level of exertion yields proportionally fewer rewards when compared to the amount of previously made gains. This occurs as the result of a continually changing reference point. This effect is commonly referred to as diminishing returns, which more accurately represents how gains are perceived in Figure 4.

The diminishing effect of gains can be explained in simple terms with a mental exercise. Imagine that you have just $\$ 100$. You see a briefcase with $\$ 1000$ at the top of a tall rope. In order to retrieve the $\$ 1000$ you must climb 25 meters up the rope to retrieve the briefcase. In this situation, most people would at least attempt to retrieve the briefcase because it offers a chance to increase your net worth by a factor of almost 10 times. Now imagine the same scenario, except in this version instead of having only $\$ 100$ you have $\$ 1$ billion. Is it still worth climbing the rope to retrieve the briefcase? The reward is now much less when compared to your net worth, and you stand to gain much less proportionally from the same amount of exertion.

An example of this can be seen in the U.S.-Mexico rivalry, which lasted from 1836 to 1893 . Between 1846 and 1848, as the result of the Mexican-American War, the United States achieved substantial rewards. The United States gained control of territory 
that is now California, Nevada, Utah, New Mexico, Texas, parts of Colorado, Wyoming, Kansas, and Oklahoma. The United States could have continued to press forward and conquer large swaths of territory. In fact, the U.S. had already gained control of several key seaports and had troops in Mexico City. The country chose, however, not to escalate the conflict further. The potential gains earned from further exertion were comparatively smaller in proportion to the gains the United States had already made.

One primary criticism of this conceptualization of how gains are valued is that if a state receives repeated gains that result from the same level of exertion, a state will be willing to focus more effort on the conflict. There are two relevant situations to consider. First, there might be a windfall situation in which a sudden or rapid gain results from a constant level of exertion. Second, there might be a situation in which a constant level of exertion is met with an increasing amount of gains. Windfall situations tend to be the result of random events, such as a sudden, unexpected breakthrough that allows an army in the field to capture a large amount of territory. In the case of windfalls, the gain is fleeting. While it may encourage short-term willingness to focus more energy on a conflict, eventually gains will normalize, resulting in the continuation of a trend of diminishing returns. For example, during the Franco-Prussian war during the siege of Metz, the entirety of the French army was forced to surrender (Fortescue 2000). This windfall would have encouraged Prussian forces to continue fighting, despite the fact that prior to that point the French and Prussian militaries had lost a relatively equal number of soldiers. In both cases, however, the gains are constrained losses, which will increase at a greater rate as effort is expended, eventually overtaking any perceived gains. 
When states are interlocked in a rivalry, they evaluate gains and losses in terms of their rival. A state will quantify its gains not only in terms of what it gains, but in terms of what their rival loses. At the same time, it will evaluate its losses in terms of what it loses, but also in terms of what its rival gains. By judging these two gains and losses simultaneously, a state determines the factors that contribute to whether or not it will continue to escalate a conflict. A state will continue to escalate a conflict in situations where the perceived gains exceed the perceived losses and cease escalating the conflict when perceived losses overcome perceived gains. This interaction between gains and losses is depicted in Figure 5.

Because the pain of perceived losses increases proportionally to a state's amount of remaining resources, the faster the rate at which a rivalry escalates, the faster the amount of perceived losses accumulates. If the amount of perceived losses increases rapidly, the shorter the duration of the rivalry should become. This should occur as the pain from the perceived loss increases, and the amount of perceived gains begins to diminish, so states will become less willing to exert themselves to escalate the rivalry. If the rivalry escalates quickly in its initial stages, the amount of perceived losses will accumulate quickly. Thus, rapid escalation in the initial years of a rivalry should lead directly to shorter duration of the rivalry. This leads to our primary hypothesis: Rivalries with higher levels of severity in their initial years will have shorter durations.

In addition to the effect of initial severity on rivalry duration, we would also expect to see that as the severity of the overall rivalry increases, the duration of the rivalry should decrease. While a situation may not have a high level of initial severity, if the overall level of severity of the rivalry increases as the rivalry continues and rivals 
spend more on escalating the conflict, the amount of perceived losses will increase more rapidly. As losses begin to accumulate more rapidly, rivals should be less willing to continue to escalate the rivalry and more inclined to end the rivalry to prevent potential future losses, as the result of further escalation. In contrast, if the severity of the rivalry drops over time, losses will accumulate more slowly, drawing out the conflict. This brings us to our second hypothesis: As the average severity of a rivalry increases, the probability that a rivalry will terminate increases.

\section{Operationalization and Methodology}

\section{Sample and Selection}

Rivalry data from Klein, Goertz, and Diehl’s (2006) rivalry data-set is used as the sample for this study. The data used in this study begins with rivalry observations in 1946 and ends in 2001. The level of analysis is dyad-year. There are observations from 216 different rivalries and the data-set contains one observation per year, per rivalry from the life of the rivalry and has a total of 3,432 observations.

\section{Dependent Variables}

Rivalry termination. The dependent variable in this model is rivalry termination. Rivalry termination dates were drawn from Klein, Goertz ,and Diehl’s (2006) data-set on rivalries. Rivalries are defined as terminating in this dataset $10-15$ years after the last militarized interstate dispute. Rivalry termination is coded as (1) for the year in which a rivalry ends and (0) in all other cases with the exception of a rivalry that continues on after 2001 when the dataset ends, in which case it is coded as (1) for 2001.

\section{Independent Variables}


Average rivalry severity. The severity of a rivalry is determined by utilizing the severity score index, which measures the severity of each conflict that occurs between two rivals, developed by Klein, Goertz, and Diehl (2006). The severity score takes into account the number of conflicts between rivals, the number of casualties in a conflict, as well as the level of hostility between the parties involved. The severity score is used as a way to measure the amount of loss incurred because of the rivalry. As the rivalry becomes severe, the amount of perceived loss should increase accordingly. From these scores the average severity is calculated by taking the severity of all previous conflicts in a rivalry and dividing it by the total number of conflicts to date. In this sample, the average severity score ranges from (0) to (361).

Initial rivalry severity. Initial rivalry severity is derived from the average severity variable. The initial severity of a rivalry is calculated as the average severity of the interactions between two rivals after the first five years of a rivalry.

\section{Control Variables}

Regime change. The Polity Index, drawn from the Polity IV data-set, measures different facets of executive recruitment, constraints on the executive, regulation of political participation, and competitiveness of political participation to determine the level of democracy or autocracy within a state. Polity Index scores range from (-10), fully institutionalized autocratic regimes, to $(+10)$ fully institutionalized democratic regimes. The polity change variable controls for significant changes in the political structure or regime of a state. A six point movement in the polity score of a state represents a move from consolidated democracy or authoritarianism to anocracy, from anocracy to democracy or authoritarianism, or from an authoritarian anocracy to a democratic 
anocracy, or vice versa. For cases when either party of a dyad has a change in polity score greater than six points, polity change is coded as (1). If neither state has a polity change of six or greater Polity Change is coded as (0).

Past polity change. In order to account for major polity changes in the past that could affect current decision making processes we utilize a second polity change variable, which measures major changes in the political structure in the past five years. A five-year period was selected because it is long enough to account for the effects of recent political changes that may affect decision-making. This period is short enough that it does not take into account changes in polity that no longer have major effects because the changes in behavior that resulted from those changes in polity are now institutionalized and have become the status quo. If a change of more than six points on the Polity Index occurs in a country in the past five years, polity change is coded as (1). Otherwise it is coded as (0).

Composite index of national capability ratio. The Composite Index of National Capability is drawn from the National Material Capabilities data-set developed by the Correlates of War Project. A country’s CINC score is derived from their iron and steel production, military expenditures, military personnel, energy consumption, population, and size of their urban population. The CINC Ratio variable controls for wide disparities in power of rival nations. The ratio is calculated by dividing the CINC score of one rival in the dyad by the CINC score of the second rival in the dyad.

Balance of power. Previous research shows that changes in the balance of power may have some effect on the termination of rivalries (Bennett, 1997). We use a dichotomous variable in an attempt to account for substantial changes in the balance of 
power between two states. We set a threshold of two percent in the difference between the capabilities of two rivals from the previous year as a significant change. A two percent threshold was set because a two percent change is sensitive enough to account for major changes in power, but only occurs in about one percent of cases and is therefore uncommon enough to be considered a departure from normal fluctuations in the balance of power. If the difference in capabilities between one state in a rivalry and the second state in a rivalry, as defined by their CINC score, changes two percent or more from the previous year we deemed this to be significant, and coded it as (1). If the change from the previous year was less than two percent, its power change was coded as (0).

Presence of outside threats. Previous research indicates that the presence of outside threats has an effect on the duration of rivalries (Bennett, 1997). The presence of an outside threat is defined as the involvement of either rival in a second rivalry in the current year. If either state in a rivalry is involved in a second rivalry in the current year, the presence of an outside threat is coded as (1); otherwise it is coded as (0).

Past outside threats. In addition to controlling for the presence of outside threats in the current year, we account for outside threats in the past that may influence current decision making processes. We created a variable that accounts for the presence of an outside threat in the past that could influence current decision-making processes. If either state in a rivalry was involved in second rivalry in the last five years, the past outside threat is coded as (1). Otherwise it is coded as (0).

Democracy. Democracies and authoritarian regimes operate in different manners. Democratic states are forced to deal with losses in different ways than authoritarian regimes, because in democratic states the electorate both holds political power and must 
directly bear the cost of conflict (Kant 1795). In contrast, rulers in authoritarian regimes are often removed from the direct costs of conflicts. Additionally, previous research regarding democratic peace states that democracies are less likely to go to war with one another (Oneal and Russett 1997). This makes the way democracies interact with one another different from the way democracies interact with non-democracies in situations involving conflict. To account for this difference in behavior, democracy is coded as (1) when both countries involved in a rivalry are classified as consolidated democracies. For example, they have a score equal to or greater than (5) on the Polity Index; otherwise democracy is coded as (0).

Time. Previous research indicates that the longer a rivalry continues, the greater the probability that it will terminate (Cioffi-Revilla 1998; Bennett 1998). We introduce a time variable that measures the amount of time, in months, that has elapsed since the beginning of a rivalry as a control for this relationship.

\section{Method}

Because the dependent variable is dichotomous, a logistic regression model was utilized to predict the probability of rivalry termination as the result of the initial severity of a rivalry. The logistic regression determines which, if any, of the variables used in the model are significant. Furthermore, because the coefficients output by the logistic regression model do not correspond to a direct linear change in the dependent variable as the result of changes in the independent variable, odds ratios are also utilized in order to provide easily interpretable and meaningful coefficients.

\section{Results}


The logistic regression displayed in Table 1 shows that, while it has a significant effect on rivalry termination, increases in the initial severity of a conflict have the opposite effect than that expected by the theory put forth in this paper. Instead of an increase, higher levels of initial severity decreased the probability that a rivalry would terminate. The effect of initial severity on rivalry duration is, however, small, with a one point increase in the severity score resulting in a .4 percent decrease in the probability that the rivalry will terminate.

Additionally, the logistic regression for our second independent variable, average severity, displayed in Table 2 shows that, while it has a significant effect on rivalry termination, increases in the average severity of a conflict have the opposite effect than that expected by our theory. Instead of increasing the probability of rivalry termination, increases in average severity decrease the probability of rivalry duration. The effect of the overall severity of a rivalry shows a similar effect to that of initial severity, with a one point increase in severity score resulting in a .4 percent decrease in the probability a rivalry will terminate.

Increases in severity, instead of reducing the duration of a rivalry, resulted in a very small decrease in the probability that a rivalry will terminate. This finding could be the result of several different factors. For example, if states feel a need to justify sunk costs, this would explain why rivalries characterized by higher levels of severity have a reduced probability of termination. As the level of severity increases, the level of expended materials increases, and so too does the need to justify these costs. Therefore, we would expect to see an increase in rivalry duration as severity increases. Additionally, vengefulness on the part of rivals could also cause the increase in rivalry duration that 
coincides with increases in severity, because as a rivalry escalates and states accumulate losses, states may seek to punish their rivals for losses it has incurred as the result of escalation by their rival.

In addition to the two independent variables in this study, two of the control variables in this model were shown to be significant. In the first model, but not in the second model, time had a small but significant impact on increasing the probability of rivalry termination. For every month of elapsed time in a rivalry, the chance a rivalry would terminate increased by .02 percent, which equates to approximately a 13 percent increase in the probability of termination for the longest rivalries in our sample. The finding that rivalries are more likely to terminate as they increase in duration is congruent with previous findings by Cioffi-Revilla (1998) and Bennett (1998).

In both models, polity change in the last five years also showed a significant effect on the probability of rivalry termination. Polity change, however, in both models was linked to a decreased probability of rivalry termination. This conflicts with previous findings by Bennett (1998), which show that polity changes increase the probability of rivalry termination. This conflicting finding could be the result of a difference in samples. Bennett's (1998) sample is smaller, consisting of observations from only 63 rivalries, whereas the same for this study contains observations from over 300 rivalries. This difference in results could also be the result of differences in the measurement for changes in polity, Bennett's (1998) measurement for polity changes accounted for the number of polity changes that occurred in each rivalry, whereas the measurements for polity change in this study accounted only for whether or not a change in polity occurred. Furthermore, there is a difference in the method of analysis used in this study and 
Bennett’s (1998) study, as this study utilizes a logistic regression and Bennett utilizes a proportional hazard model. These differences could account for the disparity in the results found by this study and previous studies.

\section{Conclusion}

This study's findings were contrary to our initial theory that the initial severity and the average severity of rivalries were both linked to increased rivalry duration. Second, my findings were contrary to previous studies indicating that polity changes may increase rivalry duration. Third, this study found, in accordance with previous studies that as rivalries increase in duration, the probability that they will terminate increases. The results of this study suggest that the measure of severity used in this study may not adequately reflect the total cost of all losses incurred from the escalation of a rivalry and that future research is needed to clarify the relationship between polity changes and rivalry termination. Future research on the effect of gains and losses should include multiple measures of losses and include not only number of casualties, but the loss of political and economic capital, losses in territory, and material goods. 


\section{References}

Bennett, D.S. 1996. “Bargaining, and The End of Interstate Rivalry.” International Studies Quarterly 40(2), 157-183.

Bennett, D.S. 1997. “Measuring Rivalry Termination, 1816-1992.” Journal of Conflict Resolution, 41(2), 227-254.

Bennett, D.S. 1998. “Integrating and Testing Models of Rivalry Duration.” American Journal of Political Science 42(4), 1200-1232.

Cioffi-Revilla, C. 1998. "Struggles for Power: A Punctuated Equilibrium Model of Interstate Rivalries.” In The Dynamics of Enduring Rivalries, P.F. Diehl, ed.Urbana, IL: University of Illinois Press.

Bennett, D. S. and Stam, A. 2000. "EUGene: A Conceptual Manual”. Version 3.204. International Interactions 26:179-204. Retrieved at http://eugenesoftware.org.

Colaresi, M. 2001. "Shocks to the System: Great Power Rivalry and the Leadership Long Cycle.” Journal of Conflict Resolution 45(5), 569-593.

Colaresi, M., and Cornwell, D. 2002. "Holy Trinities, Rivalry Termination and Conflict.”International Interactions 28, 325-354.

Colaresi, M. 2004. "When Doves Cry: International Rivalry, Unreciprocated Cooperation, and Leadership Turnover.” American Journal of Political Science 48(3), 555-570.

Fortescue, W. 2000. The Third Republic in France, 1870-1940: conflicts and continuities. London, UK: Routledge.

Geller, D.S. 1993. “Power differentials and war in rival dyads.” International Studies Quarterly 37, 174-193.

Gibler, D. 1997. "Control the Issues, Control the Conflict: The Effects of Alliances That Settle Territorial Issues on Interstate Rivalries.” International Interactions 22, 341-68

Goertz, G. and Diehl, P.F. 1992. “The Empirical Importance of Enduring Rivalries. International Interactions 18, 151-163.

Goertz, G. and Diehl, P.F. 1995. "The Initiation and Termination of Enduring Rivalries:The Impact of Political Shocks.” American Journal of Political Science 39(1), 30-53. 
Goertz, G. and Diehl, P.F. 2000. War and Peace in International Rivalry. Ann Arbor: University of Michigan Press.

Goertz, G., Jones, B., and Diehl, P.F. 2005. "Maintenance Processes in International Rivalries.” Journal of Conflict Resolution 49(5), 742-769.

Hensel, P.R., Goertz, G. and Diehl, P.F. 2000. “The Democratic Peace and Rivalries.” Journal of Politics 63(4), 1173-1188.

Higgs, R. 1988. “U.S. Military Spending in The Cold War Era: Opportunity Costs, Foreign Crises, and Domestic Constraints.” Cato Policy Analysis, 114.

Huth, P. 1996. “Enduring Rivalries and Territorial Disputes, 1950-1990.” Conflict Management and Peace Science 15(7), 7-40.

Kahneman, D. and Tversky, A. 1979. "Prospect Theory: An Analysis of Decision under Risk.” Econometrica 47(2), 263-292.

Kahneman, D. and Tverksy, A. 1986. "Rational Choice and the Framing of Decisions.” Journal of Business, 59(4), S251-S278.

Kant, I. 1903. Perpetual Peace. (M.C. Smith, Trans.). New York, NY: McMillan Publishing. (Original work published 1795).

Klein, J.P., Goertz, G, and Diehl, P.F. 2006. “The New Rivalry Dataset: Procedures and Patterns.” Journal of Peace Research 43(3), 331-348.

Lebow, R. 1995. “The Search for Accommodation: Gorbachev in Comparative Perspective.” In R. Lebow and T. Risse. (eds.) Understanding the End of the Cold War. Baltimore: Johns Hopkins University Press.

Levy, J. 1992. "Prospect Theory and International Relations: Theoretical Applications and Analytical Problems.” Political Psychology 13(2), 283-310.

Levy, J. 2000. "The Implications of Framing and Loss Aversion for International Conflict.” In M.I. Midlarsky (ed.), Handbook of War Studies II. Ann Arbor: University of Michigan Press.

Maoz, Z. and Mor, B.D. 1996. "Enduring Rivalries: The Early Years.” InternationalPolitical Science Review 17(2), 141-160.

Marshall, M.G. and Jaggers, K. 2010. "Polity IV Project: Political Regime Characteristics and Transitions, 1800-2010.” Version p4v2010. Vienna, VA. Center for Systemic Peace. Retrieved at http://www.systemicpeace.org/polity/polity4.htm 
Oneal, J. and Russett, B. 1997. "The Classical Liberals Were Right:

Democracy,Interdependence, and Conflict 1950-1985.” International Studies Quarterly 41(2), 267-293.

Prins, B. and Daxecker, U. 2008. "Committed To Peace: liberal Institutions and the Termination of Rivalry.” British Journal of Political Science 38(1), 17-43.

Quattrone, G.A. and Tversky, A. 1988. “Contrasting Rational and Psychological Analyses of Political Choice.” American Political Science Review 82(3), 719-736.

Singer, J.D. 1987. "Reconstructing the Correlates of War Dataset on Material Capabilities of States, 1816-1985". Version 3.02. International Interactions 14:115-32. Retrieved at http://www.correlatesofwar.org.

Thompson, W. 1999. “The Evolution of Great Power Rivalry: The Anglo-American Case.” In W. Thompson, (ed.). The Evolution of Great Power Rivalries. Columbia: University of South Carolina Press.

Thompson, W. 2001. "Identifying Rivals and Rivalries in World Politics.” InternationalStudies Quarterly 45(4), 557-586.

Vasquez, J. 1998. "The Evolution of Multiple Rivalries Prior to the Second World War in the Pacific.” In The Dynamics of Enduring Rivalries. P.F. Diehl, ed. Urbana: University of Illinois Press.

World Bank. 2011. World Development Indicators and Global Development Finance Washington D.C.: World Databank. 
Loss, Perception, and Rivalry Termination 25

Table 1. Effects of Initial Severity

\begin{tabular}{|l|r|r|r|}
\hline T able 1 - Effects of Initial Severity \\
\hline Rivalry Terrmination & Odds Ratio & Std. Err. & \\
\hline Initial Severity & 0.9961 & 0.0018 & 0.027 \\
CINC Ratio & 1.0001 & 0.0005 & 0.754 \\
Balance of Power & 0.7176 & 0.7381 & 0.747 \\
Outside Threat & 0.6693 & 0.4719 & 0.569 \\
Polity Change & 1.427 & 0.5462 & 0.353 \\
Past Outside Threat & 1.0001 & 0.7188 & 1 \\
Past Po lity Change & 0.3687 & 0.116 & 0.002 \\
Both Democracies & 0.9299 & 0.3203 & 0.833 \\
Time & 1.0021 & 0.0007 & 0.002 \\
\hline \#* ${ }^{*}$, ${ }^{*}$ indicate significance at the $.01, .05$ and .10 level, respectively. \\
\hline
\end{tabular}


Loss, Perception, and Rivalry Termination 26

Table 2. Effects of Average Severity

\begin{tabular}{|c|c|c|c|}
\hline Rivalry Terrmination & Odds Ratio & Std. Err. & $|\mathrm{P}>| \mathrm{z} \mid$ \\
\hline Average Severity & 0.9968 & 0.0018 & $0.073^{*}$ \\
\hline CINC Ratio & 0.9997 & 0.0005 & 0.639 \\
\hline Balance of Power & 0.5452 & 0.557 & 0.553 \\
\hline Outside Threat & 0.7771 & 0.4884 & 0.688 \\
\hline Polity Change & 1.3367 & 0.4566 & 0.396 \\
\hline Past Outside Threat & 1.0515 & 0.6709 & 0.937 \\
\hline Past Polity Change & 0.4371 & 0.1162 & 0.002 \\
\hline Both Democracies & 1.2944 & 0.3669 & 0.363 \\
\hline Time & 0.9998 & 0.0006 & 0.775 \\
\hline
\end{tabular}


Figures 1-5 Showing Relationships among the Variables
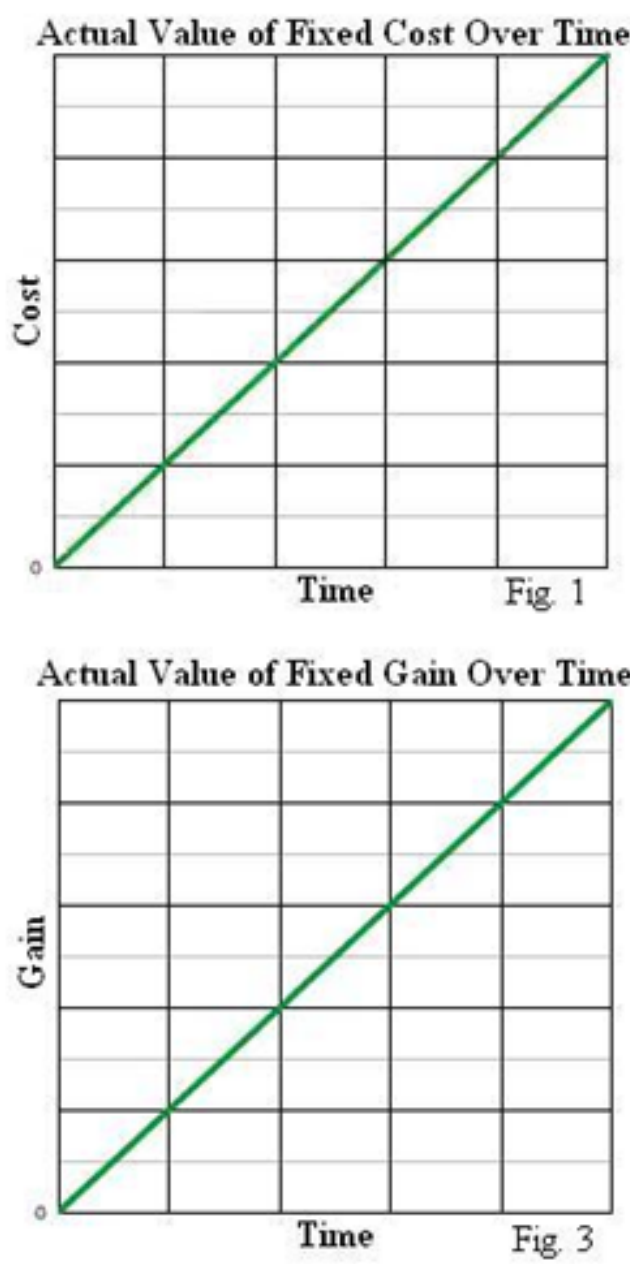

Peception of Loss Relative to Depleting Resources

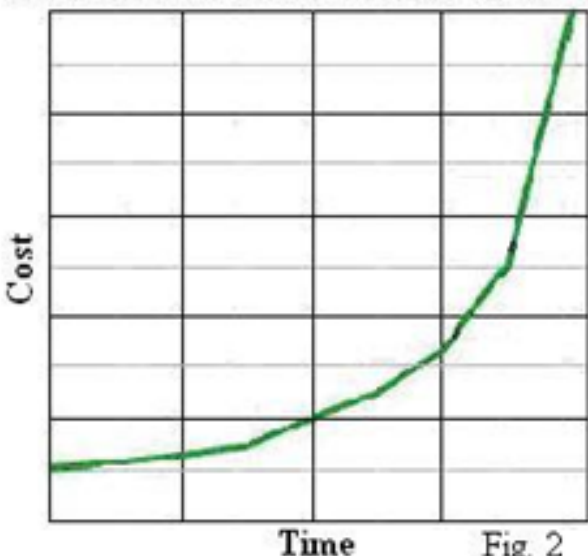

Perception of Fixed Gain Relative to Accumulating Gairs

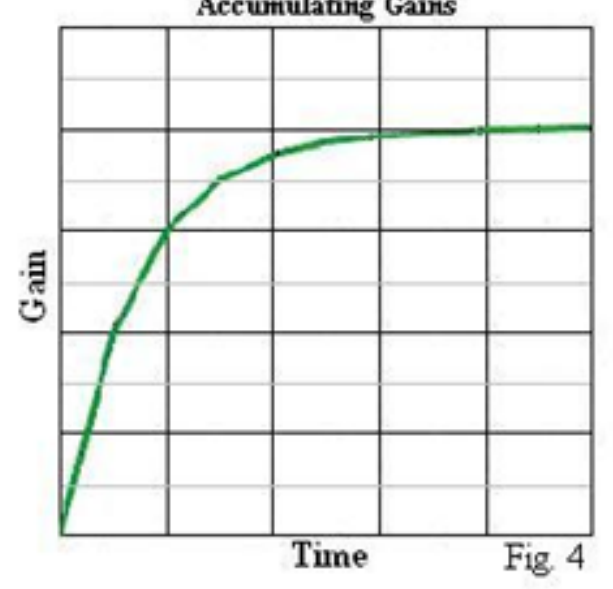

Perception of Gains vs. Losses Over Time

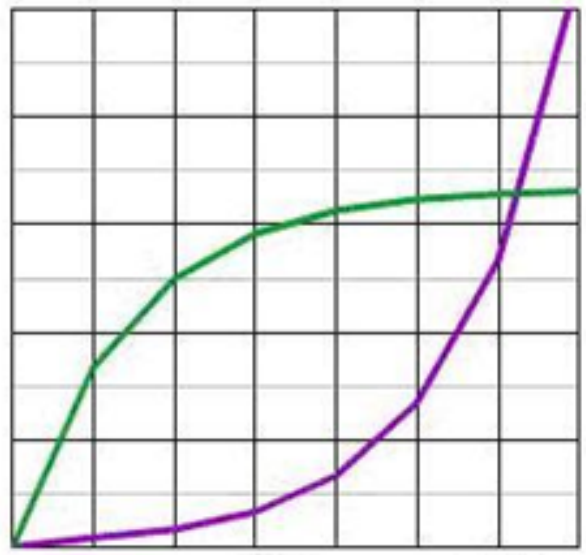

Time

Fig. 5 